Chzhao Dun, Diachenko A. Special strength preparation impact on specific components of functional provision of rowers' special work capacity. Theory and Methods of Physical education and sports. 2019; 1: 52-56

DOI:10.32652/ tmfvs.2019.1.52-56
Чжао Дун, Дяченко А. Вплив спеціальної силової підготовки на специфічні компоненти функціонального забезпечення спеціальної роботоздатності спортсменів у веслуванні академічному. Теорія і методика фрізичного виховання і спорту. 2019; 1: 52-56 DOI:10.32652/tmfvs.2019.1.52-56

\title{
ВПЛИВ СПЕЦІАЛЬНОЇ СИЛОВОЇ ПІДГОТОВКИ НА СПЕЦИФІЧНІ КОМПОНЕНТИ ФУНКЦІОНАЛЬНОГО ЗАБЕЗПЕЧЕННЯ СПЕЦАЛЬНОЇ РОБОТОЗДАТНОСТІ СПОРТСМЕНІВ У ВЕСЛУВАННІ АКАДЕМІЧНОМУ
}

\author{
Чжао Дун, Андрій Дяченко \\ Національний університет фізичного виховання і спорту, України, Київ, Україна
}

Анотація. У статті обгрунтовано вплив спеціальної силової підготовки спортсменів у веслуванні академічному на спеціальну роботоздатність в умовах компенсованого стомлення.

Мета. Оцінити вплив силової підготовки веслувальників на підвищення їхньої спеціальної роботоздатності у веслуванні академічному в умовах компенсованого стомлення.

Методи: Аналіз науково-методичної літератури, ергометрія.

Результати. В статті показано, що спеціальна силова підготовка є одним із ключових чинників розвитку спеціальної витривалості веслувальників. У поєднанні з тренувальною роботою на рівні порогу анаеробного обміну відмічено збільшення спеціальної роботоздатності веслувальників у період настання компенсованого стомлення, що розвивається на другій половині дистанції. Під впливом спеціальної фізичної підготовки із застосуванням засобів спеціальної силової підготовки зафріксовано збільшення спеціальної роботоздатності на відрізку 1000-1500 м на 4,6 \%, на дистанції 2000 м - на 4,7 \% за показниками ергометричної потужності роботи в процесі моделювання змагальної діяльності веслувальників на ергометрі Concept II. Про підвищення компенсації стомлення свідчить збільшення питомих показників легеневої вентиляції і $\mathrm{CO}_{2}$ періоду стійкого стану і розвитку втоми на 9,7%. Характеристики аеробного енергозабезпечення достовірно не змінилися.

Ключові слова: силова підготовка, веслування академічне, спеціальна роботоздатність.

\section{Chzhao Dun, Andrii Diachenko}

\section{SPECIAL STRENGTH PREPARATION IMPACT ON SPECIFIC COMPONENTS OF FUNCTIONAL PROVISION OF ROWERS' SPECIAL WORK CAPACITY}

Abstract. The article substantiates the effect of special strength preparation of rowers on special work capacity in conditions of compensated fatigue.

Objective. To evaluate the effect of strength preparation of rowers on increasing their special work capacity in academic rowing in conditions of compensated fatigue.

Methods: Analysis of scientific and methodological literature, ergometry.

Results. The article shows that special strength preparation is one of the key factors for the development of special endurance of rowers. In combination with training work at the level of anaerobic metabolism threshold, an increase in the special work capacity of the rowers during the period of compensatory fatigue developing at the second half of the distance was noted. Under the influence of special physical training with the use of means of special strength preparation, an increase in the special work capacity on 1000-1500 m segment by $4.6 \%$ was recorded, whereas at a distance of $2000 \mathrm{~m}-$ by $4.7 \%$, according to the indices of ergometric work power in the process of modeling the competitive activity of the rowers on the Concept II ergometer. An increase in the specific indices of pulmonary ventilation and CO2 period of steady state and the development of fatigue by $9.7 \%$ indicate an increase in the compensation of fatigue. Characteristics of aerobic energy supply have not significantly changed.

Keywords: strength preparation, rowing, special work capacity.

Вступ. Пошук нових підходів до вирішення проблеми підвищення спеціальної роботоздатності й збільшення спеціалізованої спрямованості тренувального процесу в підготовчому періоді є одним 3 актуальних питань сучасного спортивного тренування [5]. За наявності певної суми знань, сформованих системних підходів залишається ряд проблемних питань, що стосуються розвитку спеціальної роботоздатності веслувальників, вирішення яких може суттєво вплинути на ефективність ре- алізації наявного рухового потенціалу спортсменів [1].

Не викликає сумніву той факт, що силова підготовка спортсменів, побудована відповідно до вимог структури спеціальних локомоцій, впливае на рівень реалізації фізичної та технічної підготовленості спортсменів у процесі напруженої змагальної діяльності $[2,3]$. У веслуванні академічному оптимальний рівень і раціональний розподіл зусиль протягом подолання дистанції багато в чому 
визначає ефективність функціонального забезпечення спеціальної роботоздатності [6]. Нераціональна силова підготовка і пов'язана з нею знижена координація роботи м'язових груп знижують можливості реалізації техніки веслування, призводять до нераціонального (неекономічного) використання функціональних резервів організму [4].

Результати досліджень свідчать, що приріст спеціальної силової підготовленості веслувальників супроводжується збільшенням стійкості техніки виконання гребних локомоцій і ефективності функціонального забезпечення спеціальної роботоздатності [13, 14]. В процесі обстеження спортсменів було зареєстровано вищі показники рівня концентрації лактату крові, потужності і стійкості максимального споживання $\mathrm{O}_{2}$, поліпшення питомих показників ефективності функціонального забезпечення спеціальної роботоздатності $\mathrm{O}_{2} \cdot \mathrm{HR}, \mathrm{V}_{\mathrm{E}} \cdot \mathrm{VO}_{2}, \mathrm{HR} \cdot \mathrm{W}$ та ін. [9, 15].

Особливий інтерес викликають дані, які характеризують вплив спеціальної силової підготовки на прояв витривалості веслувальників [10, 11]. У спеціальній літературі є дані, які свідчать про збільшення спеціальної роботоздатності в процесі моделювання змагальної діяльності у веслуванні академічному на веслувальному тренажері «Concept II» [8, 14]. При цьому основні акценти в аналізі зроблено на реєстрацію характеристик стартового розгону і початкової частини дистанції 500 м [12].

Даних про вплив силової підготовки на ефективність роботи в умовах розвитку втоми, характерного для другої половини дистанції, представлено недостатньо. При цьому значення фактора компенсації стомлення і пошуку резервів розвитку цього компонента функціонального забезпечення для підвищення рівня спеціальної роботоздатності веслувальників важко переоцінити. Зі сказаного випливає, що аналіз, вивчення і переосмислення ролі і впливу спеціальної силової підготовки як одного з факторів впливу на розвиток роботоздатності веслувальників в умовах розвитку компенсованого стомлення є актуальним напрямом наукового дослідження та підставою для подальшої розробки проблеми.

Дослідження є частиною науково-дослідної роботи, проведеної Національним університетом фізичного виховання і спорту України відповідно до плану НДР НУФВСУ на 2016-2020 рр. 3 теми «Побудова тренувального процесу висококваліфікованих спортсменів, які спеціалізуються у водних видах спорту, з урахуванням вимог змагальної діяльності» (номер держреєстрації 0116U001614).

Мета дослідження - оцінити вплив силової підготовки на підвищення спеціальної роботоздатності спортсменів у веслуванні академічному в умовах компенсованого стомлення.

Методи дослідження: аналіз і узагальнення даних спеціальної літератури, ергометрія.
Результати дослідження та їх обговорення. Під час вивчення впливу силової підготовки використовували спеціалізований ергометр Concept II, для оцінки реакції кардіореспіраторної системи й енергозабезпечення - газоаналізатор Oxycon mobile.

У ході оцінювання ергометричних і фізіологічних характеристик аналізували такі показники: середня ергометрична потужність роботи на дистанції 2000 м і на відрізку дистанції 1000-1500 м (моделювання роботи на ергометрі); відносні характеристики співвідношення легеневої вентиляції, $\mathrm{CO}_{2}$ і $\mathrm{VO}_{2}$ в умовах стійкого стану (на останніх 30 с відрізка 500-1000 м) і в період розвитку втоми (на останніх 30 с відрізка 1000-1500 м). Реєстрували середні значення показників.

Експеримент проводили протягом 14 днів у підготовчому періоді річного циклу. В експерименті брали участь 28 кваліфікованих веслувальників, яких було розподілено на дві групи - контрольну та експериментальну. Експериментальна група (ЕГ) $(\mathrm{n}=14)$ використовувала засоби спеціальної силової підготовки. Було проведено 12 занять цільової силової спрямованості і 12 занять з інтенсивністю роботи на рівні порога анаеробного обміну (АТ). Розподіл навантажень в заняттях силової спрямованості проходив відповідно до поступового перерозподілу навантаження рівномірного характеру і повторних зусиль на фоні поступового збільшення інтенсивності силової роботи, характерної для змагальної діяльності веслувальників. Контрольна група (КГ) $(\mathrm{n}=14)$ основну увагу приділила розвитку аэробного енергозабезпечення роботи.

Дані попереднього тестування веслувальників обох груп виявили невеликий ступінь відмінностей характеристик ергометричної потужності і часу подолання змагальної дистанції і відрізка роботи 100-1500 м.

Порівняльний аналіз даних, представлених у таблиці 1, свідчить, що протягом експериментального періоду підготовки в рівні фізичної підготовленості веслувальників відбулись певні зміни. Так, на рівні достовірних відмінностей $(\mathrm{p}<0,05)$ під впливом засобів силової підготовки відмічено зміни спеціальної роботоздатності у спортсменів ОГ.

Достовірні зміни відбулися за показниками ергометричної потужності роботи і питомими показниками легеневої вентиляції і $\mathrm{CO}_{2}$. Характеристики співвідношення легеневої вентиляції і $\mathrm{CO}_{2}$ достовірно не змінилися. Це пов'язано з вищим рівнем стійкості споживання $\mathrm{O}_{2}$ i тенденцією до його підвищення на другій половині дистанції.

На рисунку 1 схематично представлено відмінності ступеня збільшення або зниження характеристик спеціальної роботоздатності, реакції кардіореспіраторної системи. Звертає на себе увагу зниження питомих показників легеневої вентиляції і споживання $\mathrm{O}_{2}$ в завершальній фазі на відрізках 
Таблиця 1 - Показники спортсменів, зафіксовані під час тестування на тренажері Concept II

\begin{tabular}{|c|c|c|c|c|c|c|c|c|c|c|c|c|}
\hline \multirow{3}{*}{$\begin{array}{c}\text { Статис- } \\
\text { тика }\end{array}$} & \multicolumn{6}{|c|}{ Контрольна група } & \multicolumn{6}{|c|}{ Експериментальна група } \\
\hline & \multicolumn{2}{|c|}{$\bar{W}$} & \multicolumn{4}{|c|}{ Фізіологічні показники } & \multicolumn{2}{|c|}{$\bar{W}$} & \multicolumn{4}{|c|}{ Фізіологічні показники } \\
\hline & $2000 \mathrm{M}$ & $\begin{array}{c}1000- \\
1500 \mathrm{M}\end{array}$ & $\mathrm{V}_{\mathrm{E}} \cdot \mathrm{CO}_{2}-\mathrm{I}^{*}$ & $\mathrm{~V}_{\mathrm{E}} \cdot \mathrm{VO}_{2}-\mathrm{I}^{\mathrm{t}}$ & $\mathrm{V}_{\mathrm{E}} \cdot \mathrm{CO}_{2}-\mathrm{II}^{*}$ & $\mathrm{~V}_{\mathrm{E}} \cdot \mathrm{VO}_{2}-1 \mathrm{II}^{\mathrm{m}}$ & 2000 м & $\begin{array}{c}1000- \\
1500 \mathrm{M}\end{array}$ & $\mathrm{v}_{\mathrm{E}} \cdot \mathrm{CO}_{2}$ & $\mathrm{~V}_{\mathrm{E}} \cdot \mathrm{VO}_{2}$ & $\mathrm{v}_{\mathrm{E}} \cdot \mathrm{CO}_{2}$ & $\mathrm{~V}_{\mathrm{E}} \cdot \mathrm{VO}_{2}$ \\
\hline \multicolumn{13}{|c|}{ Попередні } \\
\hline $\bar{x}$ & 431,3 & 408,6 & 31,6 & 30,0 & 32,0 & 31,1 & 430,0 & 409,0 & 31,9 & 29,9 & 31,6 & 31,2 \\
\hline$S$ & 5,2 & 6,0 & 2,3 & 2,1 & 2,0 & 2,1 & 5,0 & 5,0 & 2,3 & 2,1 & 2,0 & 2,0 \\
\hline \multicolumn{13}{|c|}{ Контрольні } \\
\hline $\bar{x}$ & $435,1^{\star \star \star}$ & 410,6 & 31,0 & 31,9 & 30,0 & 30,1 & 451,1 & $428,6^{\star \star \star}$ & 31,8 & 32,0 & $35,0^{* \star *}$ & 33,1 \\
\hline $\mathrm{S}$ & 5,7 & 4,9 & 2,1 & 2,0 & 2,1 & 2,1 & 5,7 & 4,2 & 2,0 & 1,9 & 1,9 & 2,0 \\
\hline
\end{tabular}

Примітки: "- показники зареєстровані на останніх 30 с відрізка 500-1000 м; ** - показники зареєстровані на останніх 30 с відрізка 1000-1500 м; ${ }^{* * *}$ - відмінності КГ та ЕГ достовірні при р $\leq 0,05$

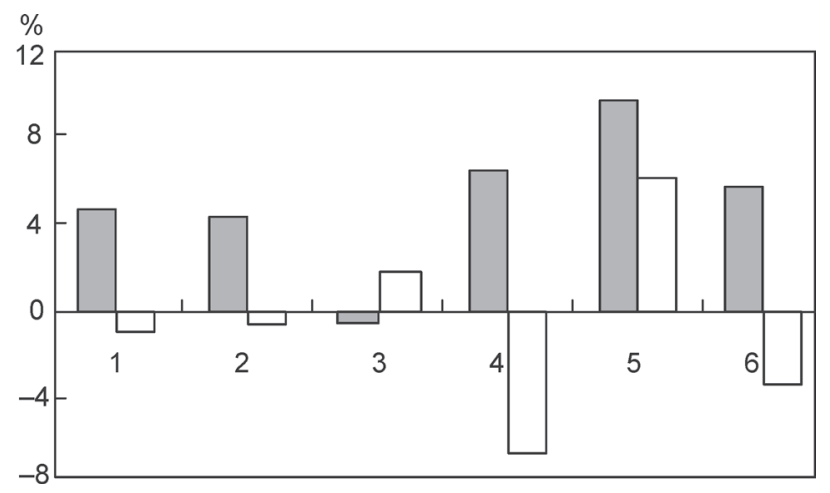

Рисунок 1 - Показники ергометричної потужності і функціональних можливостей веслувальників контрольної і експериментальної груп до і після проведення експерименту, \%:

$\square$ - експериментальна група;

- контрольна група;

Примітки: 1 - $\bar{W} 2000$ м; 2 - $\bar{W}$ 1000-1500 м; 3- $\mathrm{V}_{\mathrm{E}} / \mathrm{CO}_{2}$, зареєстровані на останніх 30 с відрізка 500-1000 м; $4-\mathrm{V}_{\mathrm{E}} / \mathrm{NO}_{2}$, зареєстровані на останніх 30 с відрізка 500-1000 м; 5 -

$\mathrm{V}_{\mathrm{E}} / \mathrm{CO}_{2}$, зареєстровані на останніх 30 с відрізка 1000-1500 м; $6-\mathrm{V}_{\mathrm{E}} / \mathrm{VO}_{2}$, зареєстровані на останніх 30 с відрізка 1000$1500 \mathrm{M}$

500-1000 і 1000-1500 м. Це свідчить про зниження ефективності аеробного енергозабезпечення. Ці характеристики, а також знижений рівень приросту питомих показників легеневої вентиляції і $\mathrm{CO}_{2}$ свідчить про зниження компенсації розвиваючого стомлення.

Очевидно, що роль силової підготовки для розвитку компенсації стомлення посилена впливом тренувальної роботи на рівні порога анаеробного обміну. Останній фактор у сукупності зі спеціальною силовою підготовкою є важливим чинником підвищення окиснювальних здатностей м'язів і пов'язаних з цим проявів витривалості спортсменів під час роботи субмаксимальної інтенсивності з вираженим силовим компонентом спеціальної функціональної підготовленості [7]. Цей фактор може бути розглянутий як підстава для проведення комплексного аналізу ефективності поєднаного впливу засобів силової й аеробної підготовки.

\section{Висновки:}

1. Спеціальна силова підготовка є одним з ключових чинників розвитку спеціальної витривалості веслувальників. У поєднанні з тренувальною роботою на рівні порога анаеробного обміну відмічено збільшення спеціальної роботоздатності спортсменів у період настання компенсованого стомлення, яке розвивається на другій половині дистанції.

2. Під впливом спеціальної фізичної підготовки з застосуванням засобів спеціальної силової підготовки показано збільшення спеціальної роботоздатності на відрізку 1000-1500 м на 4,6 \%, на дистанції 2000 м на 4,7 \% за показниками ергометричної потужності роботи в процесі моделювання змагальної діяльності веслувальників на ергометрі Concept II.

3. Про підвищення компенсації стомлення свідчить збільшення питомих показників легеневої вентиляції і $\mathrm{CO}_{2}$ періоду стійкого стану і розвитку втоми на 9,7 \%. При цьому характеристики аеробного енергозабезпечення достовірно не змінилися.

4. Актуальним напрямом досліджень є обгрунтування й практичне впровадження програми спеціальної фізичної підготовки на основі застосування режимів силової роботи з використанням спеціального силового тренажера Concept II Dyno й аеробної підготовки на рівні максимального споживання $\mathrm{O}_{2}$.

Конфлікт інтересів. Автори заявляють, що відсутній будь-який конфлікт інтересів. 


\section{Література}

1. Дьяченко АЮ. Совершенствование специальной выносливости квалифицированных спортсменов в академической гребле. - Киев: НПФ “Славутич-Дельфин”; 2004. 338 с.

2. Клешнев ВВ. Особенности гребли на эргометрах и их значение в подготовке гребцов-академистов. Теория и практика фризической культуры. 1996. Спецвып. 6: 21-26, 39.

3. Лапутин АМ. Биомеханические основы техники физических упражнений. Чернигов. ДПУ им. Т. Г. Шевченко: Науковий світ; 2001. 202 с.

4. Нечаев АВ. Распределение средств и методов совершенствования силовых качеств и выносливости в годичном тренировочном макроцикле гребцов-академистов 15-16 лет [Автореферат]. Малаховка, 2006. 24 с.

5. Платонов ВН. Периодизация спортивной тренировки. Общая теория и ее практическое применение. Киев: Олимпийская литература; 2013. 624 с.

6. Стеценко ЮН. Функциональная подготовка спортсменов - гребцов различной квалификации: учеб. пособие: Киев: УГУФВС; 1994. 191 с.

7. Уилмор ДжХ. Физиология спорта и двигательной активности. - Киев: Олимп. лит.; 1997: 85-105, 132-143, 149-215.

8. Bampouras TM, Marrin K, Sankey SP and Jones PA. (2014), «Test-retest reliability and sensitivity of the Concept2 Dyno dynamometer: practical applications», J Strength Cond Res, no 28(5): 1381-5

9. du Manoir GR, Haykowsky MJ, Syrotuik DG, Taylor DA. and Bell GJ. (2007), «The effect of high-intensity rowing and combined strength and endurance training on left ventricular systolic function and morphology», Int J Sports Med, no. 28(6): 488-94.

10. Gee TI, French DN, Howatson G, Payton SJ, Berger NJ and Thompson KG. (2011). «Does a bout of strength training affect 2,000 $\mathrm{m}$ rowing ergometer performance and rowing-specific maximal power $24 \mathrm{~h}$ later?». Eur J Appl Physiol; 111(11): 2653-62.

11. Lawton TW, Cronin JB and McGuigan MR. (2011) «Strength testing and training of rowers: a review», Sports Med, $1 ; 41(5): 413-32$.

12. Seitz LB, Reyes A, Tran TT, Saez de Villarreal E and Haff GG (2014), «Increases in lower-body strength transfer positively to sprint performance: a systematic review with meta-analysis», Sports Med, no 44(12): 1693-702

13. Smith TB. and Hopkins WG. (2012), «Measures of rowing performance», Sports Med, no. 42(4): 343-58.

14. Lawton TW, Cronin JB. and McGuigan MR. (2013), «Strength, power, and muscular endurance exercise and elite rowing ergometer performance», 27(7): 1928-35

15. Ualí I, Herrero AJ, Garatachea N, Marín PJ, Alvear-Ordenes I. and García-López D. (2012), «Maximal strength on different resistance training rowing exercises predicts start phase performance in elite kayakers», J Strength Cond Res, no. 26(4): 941-6.

\section{Literature}

1. Dyachenko AY. Improving special endurance of skilled rowers. Kiev: NPF "Skavutich-Delfin"; 2004. 338 p.

2. Kleshnev VV. Peculiarities of ergometer rowing and its significance for training rowers. Teoriya i praktika fizkultury. 1996. Special issue. 6: 21-26, 39.

3. Laputin AM. Biomechanical bases of physical exercise technique. Chernigov. DPU imeni T. H. Shevchenko: Naukovyi svit; 2001. 202 p.

4. Nechayev AV. Distribution of means and methods for improving strength capacities and endurance of rowers aged 15-16 years in annual training microcycle [Author's abstract]. Malakhovka, 2006. 24 p.

5. Platonov VN. Sports training periodization. General theory and its practical applications. Kiev: Olimpiyskaya literatura; 2013. 624 p.

6. Stetsenko YN. Functional preparation of rowers of different skill levels: teaching guide: Kiev: USUPES, $1994.191 \mathrm{p}$.

7. Wilmore JH. Sports physiology and motor activity. - Kiev: Olimpiyskaya literatura, 1997: 85-105, 132-143, 149-215.

8. Bampouras TM, Marrin K, Sankey SP and Jones PA. (2014), «Test-retest reliability and sensitivity of the Concept2 Dyno dynamometer: practical applications», J Strength Cond Res, no 28(5): 1381-5.

9. du Manoir GR, Haykowsky MJ, Syrotuik DG, Taylor DA and Bell GJ. (2007), «The effect of high-intensity rowing and combined strength and endurance training on left ventricular systolic function and morphology», Int J Sports Med, no. 28(6): 488-94.

10. Gee TI, French DN, Howatson G, Payton SJ, Berger NJ and Thompson KG. (2011), «Does a bout of strength training affect 2,000 $\mathrm{m}$ rowing ergometer performance and rowing-specific maximal power $24 \mathrm{~h}$ later?». Eur J Appl Physiol; 111(11): 2653-62.

11. Lawton TW, Cronin JB. and McGuigan, MR. (2011) «Strength testing and training of rowers: a review», Sports Med, no. 1; 41(5): 413-32.

12. Seitz LB, Reyes A, Tran TT, Saez de Villarreal E. and Haff GG (2014), «Increases in lower-body strength transfer positively to sprint performance: a systematic review with meta-analysis», Sports Med, no 44(12): 1693-702. 
13. Smith TB and Hopkins WG (2012). «Measures of rowing performance», Sports Med, no. 42(4): 343-58.

14. Lawton TW, Cronin JB. and McGuigan MR. (2013). «Strength, power, and muscular endurance exercise and elite rowing ergometer performance», 27(7): 1928-35

15. Ualí I, Herrero AJ, Garatachea N, Marín PJ, Alvear-Ordenes I and García-López D. (2012). «Maximal strength on different resistance training rowing exercises predicts start phase performance in elite kayakers», J Strength Cond Res, no. 26(4): 941-6.

Надійшла 07.02.2019

\section{Інформація про авторів}

Чжао Дун

https://orcid.org/000-0001-7808-5866

Дяченко Андрій Юрійович,

https://orcid.org/https://orcid.org/0000-0001-9781-3152 adnk2007@ukr.net

Національний університет фізичного виховання і спорту України, 03150, Київ, вул. Фізкультури, 1
Information about the authors

Dong Zhao

https//orcid.org/000-0001-7808-5866

Diachenko Andrii https://orcid.org/0000-0001-9781-3152 adnk2007@ukr.net

National University of Ukraine on Physical Education and Sport, 03150, Kyiv, Fizkul'tury str., 1. 